\title{
A TRAJETÓRIA DA EDUCAÇÃO PÚBLICA BRASILEIRA EM UMA PERSPECTIVA HISTÓRICA
}

\author{
Resenha do Livro: \\ SAVIANI, Dermeval. O Lunar de Sepé: paixão, dilemas e perspectivas na educação. \\ Campinas: Autores Associados, 2014. (Coleção Educação Contemporânea).
}

\author{
Resenha por: \\ Estefane Francisca Gonçalves ${ }^{1}$ \\ Flávio Massami Martins Ruckstadter ${ }^{2}$ \\ Vanessa Campos Mariano Ruckstadter ${ }^{3}$
}

O livro intitulado "O Lunar de Sepé: paixão, dilemas e perspectivas na educação" é uma obra que reúne estudos apresentados em conferências proferidas em diferentes ocasiões pelo professor Doutor Dermeval Saviani. Há mais de três décadas o autor contribui significativamente com publicações na área de Educação, que têm por eixo uma discussão crítica e em uma perspectiva histórica da educação pública brasileira.

Dermeval Saviani se graduou em Filosofia no ano de 1966 pela Pontifícia Universidade Católica de São Paulo (PUC/SP). Obteve o título de Doutor em Filosofia da Educação na mesma instituição em 1977. É livre-docente em História da Educação pela Universidade Estadual de Campinas (UNICAMP) desde 1966. Atualmente é professor emérito da UNICAMP e coordenador geral do Grupo de Estudos e Pesquisas "História, Sociedade e Educação no Brasil" (HISTEDBR). Em 2010 recebeu o título de Professor Emérito do Conselho Nacional de Desenvolvimento Científico e Tecnológico (CNPq). Recebeu dois prêmios Jabuti. O primeiro em 2008 pela obra "História das Ideias Pedagógicas no Brasil". Na 56 edição do prêmio no ano de 2014, o livro "Aberturas para a História da Educação" conquistou o segundo lugar na categoria Educação da premiação.

O livro é organizado em doze capítulos e inicia com um prefácio no qual o autor expõe de forma sucinta o conteúdo de cada um deles. Antes, contudo, esclarece aos leitores a origem do título. No interior do Rio Grande do Sul há uma cidade chamada São Sepé, com a qual o autor afirma que mantém uma relação emocional. O nome logo despertou sua curiosidade por não se lembrar de haver tal santo na hagiografia católica. Assim, chegou a seu conhecimento o poema popular intitulado "O Lunar de Sepé", de autoria desconhecida, sobre um índio missioneiro canonizado, não pelo Vaticano, mas sim, pelo imaginário popular. Saviani encerra seu prefácio dedicando o livro

\footnotetext{
"[...] especialmente aos professores que, nos grandes centros, nas cidades do interior e nos rincões deste país, são obrigados a sobreviver com remuneração inferior ao salário mínimo, sofrendo toda forma de constrangimento material e moral; professores sobrecarregados de aulas, submetidos ao mandonismo local e trabalhando em condições precárias com crianças também em situação de miséria moral, econômica, política, social e cultural". (SAVIANI, 2014, p. IX).
} 
O texto que abre a coletânea, intitulado "O Lunar de Sepé e a Derradeira Migração a Educação Jesuítica entre as Coroas de Espanha e Portugal", foi apresentado no VII Congresso Luso-Brasileiro de História da Educação, realizado na cidade do Porto, em Portugal, de 20 a 23 de junho de 2008. Nele o autor discute a derradeira migração dos sete povos das missões e a educação jesuítica em um contexto de disputas entre as coroas espanhola e portuguesa. Apresenta a organização das reduções jesuíticas bem como seu modelo educativo a partir do poema popular que dá título à obra. A partir do poema destaca, dentre outros, o papel dos missionários na educação das crianças, no desenvolvimento cultural e religioso, bem como o papel e significado pedagógico da imagem de São Sepé. A partir de uma reflexão do processo migratório do século XVIII o autor chega ao século XXI com um questionamento sobre os processos migratórios: "Que modelo educativo poderá dar conta dos conflitos e contradições que atravessam o fenômeno das migrações neste tumultuado mundo em que vivemos?" (SAVIANI, 2014, p. 20).

O capítulo seguinte, intitulado "Vicissitudes e Perspectivas da Pedagogia no Brasil", trata-se do registro da Conferência proferida na Universidade Estadual Paulista (UNESP), campus de São José do Rio Preto em 17 de março de 2011. Saviani discorre, com base na matriz jesuítica, sobre a pedagogia no Brasil que se desenvolveu marcada por diversas vicissitudes. No decorrer do texto o autor destaca oito vicissitudes, que se referem aos marcos na história da pedagogia brasileira. Apresenta um panorama histórico da pedagogia no Brasil, discussão que pode ser encontrada de modo aprofundado em outra obra de sua autoria, a "A Pedagogia no Brasil: história e teoria".

O capítulo três "Pedagogia, Paixão e Crítica" é resultado de uma aula inaugural do curso de Pedagogia da Universidade Estadual de Campinas (UNICAMP), proferida em 22 de março de 2011. Saviani faz algumas considerações sobre a dualidade do sentido da palavra "paixão", retornando ao calvário do educador percorrendo de modo metafórico as cinco estações: Grécia, Roma, Idade Média, época moderna e o contexto brasileiro.

O autor considera os capítulos quatro a oito como intermediários. Neles Saviani trata de questões que considera cruciais para o desenvolvimento de uma prática educativa crítica e consistente, tendo como fio condutor a identificação das vicissitudes, dos dilemas e paradoxos e a apresentação das perspectivas de solução.

O capítulo quatro, o primeiro desse bloco, recebeu o título de "Ética, Educação e Cidadania". O texto é resultado de uma Conferência apresentada no Congresso Nacional de Educação para o Pensar e Educação Sexual, em Florianópolis, no dia 25 de julho de 2001. No texto o autor apresenta cada um desses conceitos em sua relação com a prática educativa.

O capítulo cinco "Dilemas e Perspectivas da Formação de Professores no Brasil" foi apresentado na Conferência proferida no campus Catalão da Universidade Federal de Goiás (UFG), em 16 de setembro de 2010. A partir da expansão do atendimento educacional no Brasil ao longo do século XX o autor apresenta uma discussão sobre a formação de professores no contexto do problema da qualidade de ensino frente a esse processo de universalização. Para tanto, retoma historicamente os modelos de formação de professores que emergiram no século XIX, denominados por ele como "modelo dos conteúdos culturais-cognitivos de formação de professores" que tem sua ênfase no treinamento do professor no exercício de seu ofício e "modelo pedagógico-didático de formação de professores", que considera centralmente a formação pedagógico-didática. Encerra apresentando os dilemas atuais na formação de professores a partir das diretrizes 
da legislação educativa atual. Um deles é a "[...] centralidade na noção de competências versus incapacidade de superar a incompetência formativa" (SAVIANI, 2014, p. 68).

O sexto capítulo intitulado "O Direito à Educação" faz parte da apresentação na Conferência proferida em Maceió, em 26 de setembro de 2008. A discussão está pautada no direito à educação no Brasil. Para Saviani,

A cada direito corresponde um dever. Se a educação, é proclamada como um direito e reconhecido como tal pelo poder público cabe a esse poder a responsabilidade de prover os meios para que o referido direito se efetive. Eis que se impôs o entendimento de que a educação é direito do cidadão e dever do Estado (SAVIANI, 2014, p. 76).

Na sequência, “O Paradoxo da Educação Escolar Análise Crítica das Expectativas Contraditórias Depositadas na Escola" faz parte de uma pesquisa exposta na Conferência de encerramento do evento Pedagogia em Debate, apresentada na Universidade Tuiuti do Paraná, em Curitiba, no dia 11 de setembro de 2009. O debate inicial de Saviani começa a partir da pergunta: "que escola queremos?". No decorrer do texto o autor aponta alguns paradoxos, tais como: o Paradoxo da Escola Imparcial: Justiça ou Injustiça, Paradoxo da Escola Igualitária: Igualdade ou Desigualdade e o Paradoxo da Escola Equalizadora: Equidade ou Ini(E)Quidade.

O capítulo oito foi um trabalho apresentado na Conferência de abertura no II Encontro: Diálogos entre Filosofia e Educação, Seminários do DFCH, em Vitória da Conquista em 27 de setembro de 2010, com o título "Importância da Filosofia para a Educação". Para defender sua tese, o autor recorre "[...] à filosofia como uma tentativa de compreender a situação atual da educação caracterizada de forma genérica como sendo marcada pela crise de paradigmas." (SAVIANI, 2014, p.101).

Os capítulos seguintes, nove a doze, são considerados pelo professor Dermeval Saviani como subsídios para o encaminhamento das questões relativas à organização do ensino.

O primeiro desse bloco, o capítulo nove, trata-se de um texto desenvolvido para o Seminário Choque Teórico, realizado entre os dias 2 e 4 de dezembro de 1987, na Escola Politécnica da Saúde Joaquim Venâncio, da Fundação Oswaldo Cruz, no Rio de Janeiro e tem como título "Politecnia e Formação Humana". Nesse texto o autor apresenta como o mundo do trabalho norteia o princípio educativo, a ponto de estar presente na estruturação dos currículos escolares nos níveis fundamental, médio e superior.

No capítulo dez "O Futuro da Universidade entre o Possível e o Desejável” Saviani discute a contraposição, no funcionamento da universidade, entre um futuro possível, mas não desejável, e um futuro desejável, que, além de possível, como coloca o autor, merece nosso empenho e dedicação para se tornar realidade. O texto foi apresentado no Fórum "Sabedoria Universitária", realizado na Universidade Estadual de Campinas (UNICAMP), em 10 de novembro de 2009.

No penúltimo capítulo "Pós-Graduação em Educação Interdisciplinaridade e Formação de Professores", Saviani discute o conceito de interdisciplinaridade e sua relevância na formação docente. Trata-se de um artigo que resultou de uma aula inaugural do Mestrado em Formação Docente Interdisciplinar, da Universidade Estadual do Paraná (UNESPAR), campus Paranavaí, proferida pelo autor no dia 9 de setembro de 2013. 
O capítulo doze, último dessa obra, traz como título "A importância da Educação no Projeto de Desenvolvimento do País". No texto, que resultou da Palestra de abertura do $1^{\circ}$ Encontro Nacional dos Trabalhadores da Educação da CTB, em São Paulo no dia 2 de dezembro de 2011, Saviani apresenta um panorama da educação atrelada ao desenvolvimento nacional, sobretudo a partir de diretrizes neoliberais. Conclui realizando um balanço sobre o Plano Nacional de Educação, que no contexto no qual foi proferida a palestra estava na eminência de ser aprovado. A partir desse balanço, afirma que a luta maior consiste na mudança do modelo de desenvolvimento econômico do país, deslocando a educação como prioridade, tal qual aparece nos discursos.

Por meio da obra de Dermeval Saviani "O Lunar de Sepé: paixão, dilemas e perspectivas na educação", podemos ter contato com textos escritos em diferentes momentos da trajetória acadêmica do autor e da própria educação brasileira. Todos eles, contudo, apresentam uma mesma preocupação: uma educação pública brasileira efetivamente de qualidade e para todos. Os textos que compõem este livro nos ajudam a compreender temas relevantes para a educação a partir de uma perspectiva histórica e crítica, mas, mais que isso, aproxima pesquisadores e educadores do debate sobre a educação pública brasileira, em seus dilemas, contradições e paradoxos, mas também, e principalmente, em suas possibilidades de atuação e de mudança.

\footnotetext{
${ }^{1}$ Licenciada em História pela Universidade Estadual do Norte do Paraná (UENP).

2 Professor Adjunto do Centro de Ciências Humanas e da Educação, campus Jacarezinho, da Universidade Estadual do Norte do Paraná (UENP). Doutor em Educação.

${ }^{3}$ Professora Adjunta do Centro de Ciências Humanas e da Educação, campus Jacarezinho, da Universidade Estadual do Norte do Paraná (UENP). Doutora em Educação.
} 